\title{
Non-invasive Ventilatory Support in the Elderly
}

\author{
Kasiemobi E. Pulliam ${ }^{1} \cdot$ Timothy A. Pritts ${ }^{1}$ \\ Published online: 13 June 2019 \\ (C) Springer Science+Business Media, LLC, part of Springer Nature 2019
}

\begin{abstract}
Purpose of Review The first description of non-invasive ventilation use began in the 1920s. Since then, its role in patient care has evolved through increased clinical knowledge and scientific advancements. The utilization of non-invasive ventilation has broadened from initial application in acute in-hospital ICU settings to now include the outpatient settings. This review discusses the history of non-invasive ventilation and its role in acute in-hospital chronic obstructive pulmonary disease (COPD) exacerbations, cardiogenic pulmonary edema, and weaning from mechanical ventilation in the elderly. The elderly population represents a significant portion of patients hospitalized for the aforementioned conditions. These groups often have more limitations related to the use of invasive mechanical ventilation (IMV); therefore, it is essential to understand the impact of non-invasive ventilation on hospital outcomes.

Recent Findings There is strong clinical evidence supporting the use of non-invasive ventilation in patients with respiratory failure secondary to acute COPD exacerbations and cardiogenic pulmonary edema. When compared to standard medical management of these conditions, there is a consistent and significant reduction in the rate of endotracheal intubation and in-hospital mortality.

Summary The basis of non-invasive ventilation applicability has been determined by significant reduction in mortality and intubation rates. Although survival benefits have been observed, there still remain limitations to the clinical applicability of non-invasive ventilation in certain patient populations and conditions that require further investigation.
\end{abstract}

Keywords Non-invasive ventilation $\cdot$ Elderly population $\cdot$ History and literature review $\cdot$ Acute in-hospital setting

\section{Introduction}

The birth of non-invasive mechanical ventilation occurred in the late 1920s following the poliomyelitis epidemic that was notable for respiratory muscle paralysis and subsequent death in many children. Mechanical ventilation was in the form of the iron lung, a non-invasive negative-pressure respirator developed by Philip Drinker and Charles McKhann that was fashioned from a tank, a pair of vacuum cleaner blowers, a garage mechanics' creeper, and a mounted rubber collar [1]. Shortly thereafter, Motley et al. investigated the use of

This article is part of the Topical Collection on Surgical Care

Kasiemobi E. Pulliam

pulliaki@ucmail.uc.edu

Timothy A. Pritts

Timothy.pritts@uc.edu

1 Department of Surgery, University of Cincinnati, 231 Albert Sabin Way, Mail Location 0558, Cincinnati, OH 45267-0558, USA intermittent positive-pressure ventilation (IPPV) in the form of expiratory positive airway pressure (EPAP) and continuous positive airway pressure (CPAP) via a rubber mask in the treatment of acute pulmonary edema, pneumonia, GuillainBarre syndrome, near-drowning, drug overdose, and acute asthma $[2,3]$. They also identified the limitations and deleterious effects of non-invasive ventilation in the presence of hemodynamic compromise, pneumonia, and aspiration risk $[4,5]$.

Despite the introduction of polio vaccination in the early 1950s, poliomyelitis continued to be a major health care disease. Despite the success of treatment with the iron lung machine, there was a shortage of devices to meet the patient demand. Fortunately, endotracheal intubation and mechanical ventilation came into practice as a new means of supporting pulmonary function. By the 1970s, there was widespread use of IMV in newly established intensive care units (ICU). Noninvasive ventilation, in the form of intermittent positivepressure breathing, continued to be used extensively as breathing treatments in the management of certain pulmonary conditions $[4,6,7]$. 
With increased improvements in availability, scientific advancements, and understanding of mechanical ventilation came a subsequent increased recognition of the pathophysiologic consequences of invasive mechanical ventilation [4], including barotrauma and ventilator-induced lung injury. Pulmonary barotrauma or rupture of an over-distended alveolar unit occurs as a result of a sustained increase in transpulmonary pressure and is manifested as the presence of potentially life threatening extra-alveolar air $[8,9]$. Ventilator-induced lung injury, as induced by alveolar overdistension, atelectrauma, and inflammation, is characterized by a clinical picture similar to acute respiratory distress syndrome (ARDS) [10].

In 1980, Sullivan et al. described the successful use of continuous positive airway pressure (CPAP) via nasal mask in the management obstructive sleep apnea [11]. Subsequently, its use was applied to chronic respiratory failure from neuromuscular disease and symptomatic worsening nocturnal hypoventilation [12]. During the 1990s, the Consensus Conference recognized non-invasive ventilation as a valuable and essential strategy in the management of patients with acute respiratory failure [5, 13-15].

Over the last 30 years, with the supporting evidence from multiple randomized controlled trials and meta-analyses, noninvasive ventilation (NIV) has become the standard of care in the management of acute respiratory failure due to COPD, cardiogenic pulmonary edema, and prevention of weaning failure in high-risk patients [16]. These areas will be the focus of this review.

\section{Non-invasive Ventilation in the Treatment of COPD Exacerbations}

Acute exacerbations of COPD are one of the leading causes of hospitalizations in the USA. These episodes have significant economic and clinical consequences, with a mean cost of $\$ 9545$ per episode and in-hospital mortality of 4.3\% [17, 18]. Patients that survive the acute illness are at increased risk for future exacerbations and often experience significant deterioration in their quality of life [18]. Therefore, there is a need to optimize the in-hospital management of acute exacerbations of COPD. The American Thoracic Society /European Respiratory Society have defined guidelines for hospital admission, including but not limited to inadequate response to outpatient management, presence of high-risk comorbidities, worsening dyspnea, hypoxia, hypercapnia, and changes in mental status [19].

Ventilatory assistance in acute COPD exacerbation is not considered to be a primary therapy but is instead utilized as an adjunct in the prevention of respiratory acidosis until medical therapy treats the underlying cause of the acute respiratory failure [20]. Historically, numerous randomized controlled trials have demonstrated benefit to the use of NIV after failure of medical treatment as it successfully reduced the need for endotracheal intubation in comparison to conventional treatments [14, 15, 21-25]. Overall, there is not a strong mortality difference between the two groups [26].

Recent meta-analyses have studied the impact of the utilization of NIV on patients hospitalized for COPD exacerbation with acute or acute-on-chronic respiratory failure [27•, 28•]. The patients managed with NIV had a lower mortality rate, were less likely to require intubation, had shorter hospital length of stay, and had fewer complications from treatment $[27 \cdot, 28 \bullet, 29]$.

With the current mean age for patients admitted to the hospital diagnosed with an acute COPD exacerbation being approximately 70 years, it is important to study the impact of age on the use of NIV in acute COPD exacerbation [30]. When compared to patients less than 75 years old, there have been no differences in intubation or mortality rates [29].

It is also important to recognize that the elderly are more likely to have limitations to respiratory care such as "do not intubate" (DNI) orders. Despite these findings, the usefulness of non-invasive ventilation in the context of DNI orders has yet to be studied [31,32]. This is likely due to the fact the benefit of NIV in an acute COPD exacerbation has been established in several studies and it is becoming is considered to be the standard of care. Therefore, future studies may have difficulty obtaining approval from the institutional review board for ethical reasons [27•].

Despite the benefits of NIV for acute COPD exacerbations, there remains a wide rate of failure with this treatment [33]. Non-invasive ventilation failure may have been attributed to patient selection, differences in hospital care infrastructure, operator delivery and technique, and patient dyssynchrony [28•, 33-36]. The clinical impact of a specialized NIV team on the failure rate with subsequent intubation and death risk was recently studied. The authors demonstrated a lower risk of death and intubation and shorter ICU and hospital stay in patients treated with a dedicated NIV team compared to management by ICU doctors and nurses working independently [37]. These findings are likely due to more efficient use of NIV by respiratory therapists with expertise in the delivery of this mode versus the time demands and experience of other medical personnel $[26,37]$. Future studies will be needed to determine how to minimize the factors contributing to noninvasive ventilation failure.

\section{Non-invasive Ventilation in Cardiogenic Pulmonary Edema}

Acute cardiogenic pulmonary edema is another leading cause of hospitalization for the elderly [38], with in-hospital and 1year mortality rates of $12 \%$ and $40 \%$, respectively $[39,40]$. 
Similar to acute COPD exacerbations, NIV can be utilized in acute cardiogenic pulmonary edema as respiratory support in an effort to avert endotracheal intubation [39, 41].

Historically, there was no consensus as to the benefit of NIV treatment for cardiogenic pulmonary edema. Systemic reviews and meta-analysis demonstrated a reduction in the rate of intubation and mortality in patients that received NIV [42]. Shortly thereafter, the Three Interventions in Cardiogenic Pulmonary Edema (3CPO) trial, the largest randomized controlled trial on this disease, concluded there was no significant difference in short term-mortality or need for intubation between the NIV and standard therapy groups [41]. This non-inferiority study questioned the role of NIV in the management of cardiogenic pulmonary edema [43]. Several subsequent studies concluded that the use of NIV in treating cardiogenic pulmonary edema decreased the rate of intubation and in-hospital mortality [43-47].

A recent meta-analysis also demonstrated a reduction in hospital mortality, intubation rate, and ICU length of stay, quicker symptomatic improvement, and better tolerance of NIV in cardiogenic pulmonary edema as compared to standard medical therapy [48 ${ }^{\bullet}$. The trials that investigated the role of CPAP vs. bi-level positive airway pressure (BPAP) in cardiogenic pulmonary edema treatment found that there was no significant difference in hospital mortality or endotracheal intubation between the two ventilatory modes. Of note, another meta-analysis [47] demonstrated that BPAP was associated with more rapid resolution of dyspnea and improvement in oxygenation [49].

There have been few studies focused specifically on the elderly population, but given that the mean age of patients admitted for acute heart failure is greater than 70 years [50], many of the previous studies are thought to be applicable to this population. Surprisingly, a study designed to investigate the clinical efficacy of NIV in cardiogenic pulmonary edema in patients greater than 75 years of age demonstrated early clinical improvement with a reduction in the rate of intubation and $48 \mathrm{~h}$ mortality without sustained benefit during their hospital stay [51]. Due to this discrepancy, further studies may be needed to further define the role of non-invasive ventilation in cardiogenic pulmonary edema in the elderly population.

\section{Non-invasive Ventilation in Weaning from Mechanical Ventilation}

Despite the increased application of NIV in cardiogenic pulmonary edema and COPD, the utilization of invasive mechanical ventilation has increased [52]. As previously discussed, the complications of mechanical ventilation are well-known to intensivists and are associated with significant in-hospital morbidity as well as deterioration in quality of life outcomes.

The benefits of NIV when transitioning from mechanical ventilation for patients recognized to be "high risk for extubation failure" have been reported in previous studies [49]. Unfortunately, about $20-30 \%$ of patients are considered to be difficult to wean from IMV due to failure to pass a spontaneous breathing trial or needing reintubation within $48 \mathrm{~h}$ of being liberated from IMV [53, 54]. Ideally, INV could be used in patients that do not pass their spontaneous breathing trial in order to avoid the complications from prolonged intubation as well as complications associated with reintubation $[49,55-60]$. This potential use has been investigated in several randomized controlled trials and a recent systemic review found that patients weaned with non-invasive ventilation demonstrated reduced mortality and ventilator-associated pneumonia and shorter ICU and hospital stay without increasing the risk of weaning failure or reintubation [61-76]. Of note, most of these studies were exclusively or predominantly with COPD patients only $[55,77]$. Thus, future studies investigating the role of NIV as a bridge from extubation to spontaneous respiration are needed to confirm the generalizability of its use [77].

\section{Conclusion}

There is strong clinical evidence supporting the use of NIV in patients with respiratory failure secondary to acute COPD exacerbations and cardiogenic pulmonary edema. When compared to standard medical management of these conditions, there is a consistent and significant reduction in the rate of endotracheal intubation and hospital mortality $[78,79]$.

During COPD exacerbations due to increased flow resistance secondary to secretions and/or bronchospasm, there is incomplete expiration. Inspiration before a complete expiration leads to dynamic hyperinflation and subsequent reduced diaphragm strength and respiratory muscle fatigue [80, 81]. These findings are likely to be exacerbated in the elderly population due to reduced respiratory reserve. With worsening hypoxia and/or hypercapnia, work of breathing is increased which prolongs expiratory flow which all result in respiratory failure [82]. Ventilatory assistance should be considered in the presence of persistent acidosis $(\mathrm{pH}<7.35)$, hypercapnia $\left(P_{\mathrm{aCO} 2}>40-60 \mathrm{mmHg}\right)$ and tachypnea (RR $>24$ breaths/ min) [83]. The utilization of NIV unloads the respiratory muscles and augments alveolar ventilation and improvement in oxygenation and ventilation [20].

In cardiogenic pulmonary edema, cardiac failure results in increased pressure in the pulmonary arteries, triggering extravasation of fluid into the interstitium and eventually 
the alveoli [48•]. This increase in extravascular fluid in the lungs precipitates respiratory failure due to a reduction in lung volume and respiratory system compliance as well as an increase in airway resistance [84]. Non-invasive ventilation in cardiogenic pulmonary edema should be initiated when dyspnea, tachypnea, accessory muscles use, and/or paradoxical abdominal breathing are associated with impaired gas exchange [45]. Non-invasive ventilation in cardiogenic pulmonary edema prevents alveolar collapse and reduces the rate of intra-alveolar fluid accumulation while improving pulmonary compliance [48•], reducing the work of breathing, increasing cardiac output, and improving oxygenation [20].

Survival benefits have been shown for NIV in patients experiencing difficulty transitioning off of IMV after passing a spontaneous breathing trial or high risk for extubation failure patients. There is a potential use for NIV in weaning from mechanical ventilation after a failed spontaneous breathing trial, but more studies are needed in order to determine its generalizability to other causes of weaning failure secondary to respiratory failure.

Over the past 30 years, there have been significant advances in respiratory care in the critically ill patient but there still remain limitations for the applicability of NIV in these and other conditions. Although survival benefit has been demonstrated in specific clinical conditions, it appears NIV is underutilized [85-87] and higher rates of failure with the use of non-invasive ventilation in high volume hospitals [33]. Although major complications such as pneumothorax and pneumonia are less frequent with the use of NIV as compared to intubation, complications such as air leak, mask discomfort, skin breakdown, eye irritation, sinus congestion, oronasal desiccation, and dyssynchrony can contribute to the adverse outcomes $[48 \cdot, 78,88,89]$. These discrepancies are likely attributable to patient selection, need for increased patient supervision, experience of staff with non-invasive ventilation, and availability of this mode $[13,90]$. The benefits of the implementation of specialized non-invasive ventilation teams have previously been identified [37] and should prompt further investigation. Ideally, clear guidelines associated with education and training programs would be implemented to optimize the role for and application of non-invasive ventilation in the management of acute respiratory failure [91].

\section{Compliance with Ethical Standards}

Conflict of Interest Kasiemobi E. Pulliam and Timothy A. Pritts each declare that they have no conflict of interest.

Human and Animal Rights and Informed Consent This article does not contain any studies with human or animal subjects performed by any of the authors.

\section{References}

Papers of particular interest, published recently, have been highlighted as:

- Of importance

1. Drinker PA, McKhann CF 3rd. Landmark perspective: the iron lung. First practical means of respiratory support. JAMA. 1986;255(11):1476-80.

2. Motley HL, Cournand A, et al. Intermittent positive pressure breathing; a means of administering artificial respiration in man. $\mathrm{J}$ Am Med Assoc. 1948;137(4):370-82.

3. Motley HL, Lang LP, Gordon B. Use of intermittent positive pressure breathing combined with nebulization in pulmonary disease. Am J Med. 1948;5(6):853-6.

4. Pierson DJ. History and epidemiology of noninvasive ventilation in the acute-care setting. Respir Care. 2009;54(1):40-52.

5. Pierson DJ. Noninvasive positive pressure ventilation: history and terminology. Respir Care. 1990;42(4):370-9.

6. Baker JP. Magnitude of usage of intermittent positive pressure breathing. Am Rev Respir Dis. 1974;110(6 Pt 2):170-7.

7. Murray JF. Review of the state of the art in intermittent positive pressure breathing therapy. Am Rev Respir Dis. 1974;110(6 Pt 2): 193-9.

8. Pingleton SK. Barotrauma in acute lung injury: is it important? Crit Care Med. 1995;23(2):223-4.

9. Haake R, Schlichttg R, Ulstad DR, Henschen RR. Barotrauma. Pathophysiology, risk factors, and prevention. Chest. 1987;91(4): 608-13.

10. Tremblay LN, Slutsky AS. Ventilator-induced injury: from barotrauma to biotrauma. Proc Assoc Am Physicians. 1998;110(6): 482-8.

11. Sullivan CE, et al. Reversal of obstructive sleep apnoea by continuous positive airway pressure applied through the nares. Lancet. 1981;1(8225):862-5.

12. Kerby GR, Mayer LS, Pingleton SK. Nocturnal positive pressure ventilation via nasal mask. Am Rev Respir Dis. 1987;135(3):73840.

13. Bersten AD, Holt AW, Vedig AE, Skowronski GA, Baggoley CJ. Treatment of severe cardiogenic pulmonary edema with continuous positive airway pressure delivered by face mask. N Engl J Med. 1991;325(26): 1825-30.

14. Bott J, Carroll MP, Conway JH, Keilty SEJ, Ward EM, Brown AM, et al. Randomised controlled trial of nasal ventilation in acute ventilatory failure due to chronic obstructive airways disease. Lancet. 1993;341(8860):1555-7.

15. Brochard L, Mancebo J, Wysocki M, Lofaso F, Conti G, Rauss A, et al. Noninvasive ventilation for acute exacerbations of chronic obstructive pulmonary disease. N Engl J Med. 1995;333(13):81722.

16. Ambrosino N, Vagheggini G. Noninvasive positive pressure ventilation in the acute care setting: where are we? Eur Respir J. 2008;31(4):874-86.

17. Perera PN, Armstrong EP, Sherrill DL, Skrepnek GH. Acute exacerbations of COPD in the United States: inpatient burden and predictors of costs and mortality. COPD. 2012;9(2):131-41.

18. Halpin DM, Miravitlles M, Metzdorf N, Celli B. Impact and prevention of severe exacerbations of COPD: a review of the evidence. Int J Chron Obstruct Pulmon Dis. 2017;12:2891-908.

19. Celli BR, MacNee W, Force AET. Standards for the diagnosis and treatment of patients with COPD: a summary of the ATS/ERS position paper. Eur Respir J. 2004;23(6):932-46.

20. Organized jointly by the American Thoracic Society, t.E.R.S.t.E.S.o.I.C.M., F. the Societe de Reanimation de Langue, 
and D. approved by Ats Board of Directors. International Consensus Conferences in Intensive Care Medicine: noninvasive positive pressure ventilation in acute Respiratory failure. Am J Respir Crit Care Med. 2001;163(1):283-91.

21. Conti G, Antonelli M, Navalesi P, Rocco M, Bufi M, Spadetta G, et al. Noninvasive vs. conventional mechanical ventilation in patients with chronic obstructive pulmonary disease after failure of medical treatment in the ward: a randomized trial. Intensive Care Med. 2002;28(12):1701-7.

22. Kramer N, Meyer TJ, Meharg J, Cece RD, Hill NS. Randomized, prospective trial of noninvasive positive pressure ventilation in acute respiratory failure. Am J Respir Crit Care Med. 1995;151(6):1799-806.

23. Angus RM, Ahmed AA, Fenwick LJ, Peacock AJ. Comparison of the acute effects on gas exchange of nasal ventilation and doxapram in exacerbations of chronic obstructive pulmonary disease. Thorax. 1996;51(10):1048-50.

24. Celikel T, et al. Comparison of noninvasive positive pressure ventilation with standard medical therapy in hypercapnic acute respiratory failure. Chest. 1998;114(6):1636-42.

25. Plant PK, Owen JL, Elliott MW. Early use of non-invasive ventilation for acute exacerbations of chronic obstructive pulmonary disease on general respiratory wards: a multicentre randomised controlled trial. Lancet. 2000;355(9219):1931-5.

26. Mehta S, Hill NS. Noninvasive ventilation. Am J Respir Crit Care Med. 2001;163(2):540-77.

27. Osadnik CR, et al. Non-invasive ventilation for the management of acute hypercapnic respiratory failure due to exacerbation of chronic obstructive pulmonary disease. Cochrane Database Syst Rev. 2017;7:CD004104 Meta-analysis 17 randomized controlled trials published from 1998-2010. This resource is a thorough analysis of not only the primary outcomes of mortality risk and rate of intubation but also listing potential sources of bias and risk of bias for all the included studies.

28. Wedzicha J. A. E. C.-C, Miravitlles M, Hurst JR, Calverley PM, Albert RK, Anzueto A, ... Krishnan J. A. A. C.-C. Management of COPD exacerbations: a European Respiratory Society/American Thoracic Society guideline. Eur Respir J. 2017;49(3) https:/doi. org/10.1183/13993003.00791-2016 Clinical recommendations were formulated by experts on the Task Force of COPD based on a systemic review and meta-analysis of 21 randomized controlled trials. This resource includes a statement of the quality of evidence as well as a grade for the recommendation (strong/conditional). For example, recommendations considered to be "strong recommendation" represent interventions where the benefits outweigh the adverse affects.

29. Nicolini A, Santo M, Ferrera L, Ferrari-Bravo M, Barlascini C, Perazzo A. The use of non-invasive ventilation in very old patients with hypercapnic acute respiratory failure because of COPD exacerbation. Int J Clin Pract. 2014;68(12):1523-9.

30. Wier LM, et al. Overview of hospitalizations among patients with COPD, 2008: Statistical Brief \#106. In: Healthcare Cost and Utilization Project (HCUP) Statistical Briefs; 2006. Rockville (MD).

31. Nava S, Grassi M, Fanfulla F, Domenighetti G, Carlucci A, Perren A, et al. Non-invasive ventilation in elderly patients with acute hypercapnic respiratory failure: a randomised controlled trial. Age Ageing. 2011;40(4):444-50.

32. Corral-Gudino L, Jorge-Sánchez RJ, García-Aparicio J, HerreroHerrero JI, López-Bernús A, Borao-Cengotita-Bengoa M, et al. Use of noninvasive ventilation on internal wards for elderly patients with limitations to respiratory care: a cohort study. Eur J Clin Investig. 2011;41(1):59-69.

33. Mehta AB, Douglas IS, Walkey AJ. Hospital noninvasive ventilation case volume and outcomes of acute exacerbations of chronic obstructive pulmonary disease. Ann Am Thorac Soc. 2016;13(10): 1752-9.

34. Luo Z, et al. High-intensity versus low-intensity noninvasive positive pressure ventilation in patients with acute exacerbation of chronic obstructive pulmonary disease (HAPPEN): study protocol for a multicenter randomized controlled trial. Trials. 2018;19(1): 645.

35. Fisher KA, Mazor KM, Goff S, Stefan MS, Pekow PS, Williams LA, et al. Successful use of noninvasive ventilation in chronic obstructive pulmonary disease. How do high-performing hospitals do it? Ann Am Thorac Soc. 2017;14(11):1674-81.

36. Lopez-Campos JL, Jara-Palomares L, Muñoz X, Bustamante V, Barreiro E. Lights and shadows of non-invasive mechanical ventilation for chronic obstructive pulmonary disease (COPD) exacerbations. Ann Thorac Med. 2015;10(2):87-93.

37. Vaudan S, Ratano D, Beuret P, Hauptmann J, Contal O, Garin N. Impact of a dedicated noninvasive ventilation team on intubation and mortality rates in severe COPD exacerbations. Respir Care. 2015;60(10):1404-8.

38. McDermott, K.W.E., Anne; Sun, Ruirui. Trends in hospital inpatient stays in the United States, 2005-2014. Statistical Brief \#225. Healthcare Cost and Utilization Project (HCUP) Statistical Briefs 2017.

39. Girou E, Brun-Buisson C, Taillé S, Lemaire F, Brochard L. Secular trends in nosocomial infections and mortality associated with noninvasive ventilation in patients with exacerbation of COPD and pulmonary edema. JAMA. 2003;290(22):2985-91.

40. Nieminen MS, Böhm M, Cowie MR, Drexler H, Filippatos GS Jondeau G, et al. Executive summary of the guidelines on the diagnosis and treatment of acute heart failure: the Task Force on Acute Heart Failure of the European Society of Cardiology. Eur Heart J. 2005;26(4):384-416.

41. Gray A, Goodacre S, Newby DE, Masson M, Sampson F, Nicholl J, et al. Noninvasive ventilation in acute cardiogenic pulmonary edema. N Engl J Med. 2008;359(2):142-51.

42. Masip J, Roque M, Sánchez B, Fernández R, Subirana M, Expósito JA. Noninvasive ventilation in acute cardiogenic pulmonary edema: systematic review and meta-analysis. JAMA. 2005;294(24): 3124-30.

43. Potts JM. Noninvasive positive pressure ventilation: effect on mortality in acute cardiogenic pulmonary edema: a pragmatic metaanalysis. Pol Arch Med Wewn. 2009;119(6):349-53.

44. Goodacre SW, Gray A, Newby D. Errors in meta-analysis regarding the 3CPO trial. Ann Intern Med. 2010;153(4):277-8 author reply 278.

45. Bello G, De Santis P, Antonelli M. Non-invasive ventilation in cardiogenic pulmonary edema. Ann Transl Med. 2018;6(18):355.

46. Weng CL, Zhao YT, Liu QH, Fu CJ, Sun F, Ma YL, et al. Metaanalysis: noninvasive ventilation in acute cardiogenic pulmonary edema. Ann Intern Med. 2010;152(9):590-600.

47. Mariani J, Macchia A, Belziti C, DeAbreu M, Gagliardi J, Doval H, et al. Noninvasive ventilation in acute cardiogenic pulmonary edema: a meta-analysis of randomized controlled trials. J Card Fail. 2011;17(10):850-9.

48. Vital FM, Ladeira MT, Atallah AN. Non-invasive positive pressure ventilation (CPAP or bilevel NPPV) for cardiogenic pulmonary oedema. Cochrane Database Syst Rev. 2013;(5): CD005351 https://doi.org/10.1002/14651858.CD005351.pub3. A metaanalysis of 32 randomized controlled trials outlining the primary outcomes of mortality risk, rate of intubation, and the GRADE approach to assess the quality of evidence for each outcome.

49. S.K., E. Use of noninvasive ventilation to facilitate weaning from mechanical ventilation. In: Noninvasive mechanical ventilation and difficult weaning in critical care. Cham: Springer; 2016.

50. Kurmani S, Squire I. Acute heart failure: definition, classification and epidemiology. Curr Heart Fail Rep. 2017;14(5):385-92. 
51. L'Her E, et al. Noninvasive continuous positive airway pressure in elderly cardiogenic pulmonary edema patients. Intensive Care Med. 2004;30(5):882-8.

52. Mehta AB, Syeda SN, Wiener RS, Walkey AJ. Epidemiological trends in invasive mechanical ventilation in the United States: a population-based study. J Crit Care. 2015;30(6):1217-21.

53. Heunks LM, van der Hoeven JG. Clinical review: the ABC of weaning failure — a structured approach. Crit Care. 2010;14(6):245.

54. Boles JM, Bion J, Connors A, Herridge M, Marsh B, Melot C, et al. Weaning from mechanical ventilation. Eur Respir J. 2007;29(5): 1033-56.

55. Epstein SK. Noninvasive ventilation to shorten the duration of mechanical ventilation. Respir Care. 2009;54(2):198-208 discussion 208-11.

56. Esteban A, Frutos-Vivar F, Ferguson ND, Arabi Y, Apezteguía C, González M, et al. Noninvasive positive-pressure ventilation for respiratory failure after extubation. N Engl J Med. 2004;350(24): 2452-60.

57. Hilbert G, Gruson D, Portel L, Gbikpi-Benissan G, Cardinaud JP. Noninvasive pressure support ventilation in COPD patients with postextubation hypercapnic respiratory insufficiency. Eur Respir J. 1998;11(6):1349-53.

58. Jiang JS, Kao SJ, Wang SN. Effect of early application of biphasic positive airway pressure on the outcome of extubation in ventilator weaning. Respirology. 1999;4(2):161-5.

59. Nava S, Gregoretti C, Fanfulla F, Squadrone E, Grassi M, Carlucci A, et al. Noninvasive ventilation to prevent respiratory failure after extubation in high-risk patients. Crit Care Med. 2005;33(11):246570.

60. Ferrer M, Valencia M, Nicolas JM, Bernadich O, Badia JR, Torres A. Early noninvasive ventilation averts extubation failure in patients at risk: a randomized trial. Am J Respir Crit Care Med. 2006;173(2):164-70.

61. Nava S, Ambrosino N, Clini E, Prato M, Orlando G, Vitacca M, et al. Noninvasive mechanical ventilation in the weaning of patients with respiratory failure due to chronic obstructive pulmonary disease. A randomized, controlled trial. Ann Intern Med. 1998;128(9): 721-8.

62. Girault $\mathrm{C}$, et al. Noninvasive ventilation as a systematic extubation and weaning technique in acute-on-chronic respiratory failure: a prospective, randomized controlled study. Am J Respir Crit Care Med. 1999;160(1):86-92.

63. Ferrer M, Esquinas A, Arancibia F, Bauer TT, Gonzalez G, Carrillo A, et al. Noninvasive ventilation during persistent weaning failure: a randomized controlled trial. Am J Respir Crit Care Med. 2003;168(1):70-6

64. Vaschetto R, Turucz E, Dellapiazza F, Guido S, Colombo D, Cammarota G, et al. Noninvasive ventilation after early extubation in patients recovering from hypoxemic acute respiratory failure: a single-centre feasibility study. Intensive Care Med. 2012;38(10): 1599-606.

65. Trevisan CE, Vieira SR, W. Research Group in Mechanical Ventilation. Noninvasive mechanical ventilation may be useful in treating patients who fail weaning from invasive mechanical ventilation: a randomized clinical trial. Crit Care. 2008;12(2):R51.

66. Collaborating Research Group for Noninvasive Mechanical Ventilation of Chinese Respiratory, S. Pulmonary infection control window in treatment of severe respiratory failure of chronic obstructive pulmonary diseases: a prospective, randomized controlled, multi-centred study. Chin Med J (Engl). 2005;118(19): 1589-94.

67. Prasad SB, Chaudhry D, Khanna R. Role of noninvasive ventilation in weaning from mechanical ventilation in patients of chronic obstructive pulmonary disease: an Indian experience. Indian J Crit Care Med. 2009;13(4):207-12.
68. Zou SH, Zhou R, Chen P, Luo H, Xiang XD, Lu YD, et al. Application of sequential noninvasive following invasive mechanical ventilation in COPD patients with severe respiratory failure by investigating the appearance of pulmonary-infection-control-window. Zhong Nan Da Xue Xue Bao Yi Xue Ban. 2006;31(1):120-4.

69. Chen J, Qiu D, Tao D. Time for extubation and sequential noninvasive mechanical ventilation in COPD patients with exacerbated respiratory failure who received invasive ventilation. Zhonghua Jie He He Hu Xi Za Zhi. 2001;24(2):99-100.

70. Rabie Agmy G, Metwally M. Noninvasive ventilation in the weaning of patients with acute-on-chronic respiratory failure due to COPD. Egyptian J Chest Dis Tuberculosis. 2012;2012:84-91.

71. Tawfeek M, Ali-Elnabtity A. Noninvasive proportional assist ventilation may be useful in weaning patients who failed a spontaneous breathing trial. Egyptian J Anaesthes. 2012;28:89-94.

72. Rabie GM, Mohamed AZ, Mohamed RN. Noninvasive ventilation in the weaning of patients with acute-on-chronic respiratory failure due to COPD. CHEST. 2004;126(4):755S.

73. Wang X, Du X, Zhang W. Observation of the results and discussion on the timing of transition from invasive mechanical ventilation to noninvasive ventilation in COPD patients with concomitant acute respiratory failure. Shandong Med J. 2004;44:4-6.

74. Zheng R, Liu L, Yang Y. Prospective randomized controlled clinical study of sequential noninvasive following invasive mechanical ventilation in patients with acute respiratory failure induced COPD. Chinese J Emerg Med. 2005;14:21-5.

75. Hill N, Lin D, Levy M. Noninvasive positive pressure ventilation (NPPV) to facilitate extubation after acute respiratory failure: a feasibility study. Am J Respir Crit Care Med. 2000;161:A263.

76. Girault C, Bubenheim M, Abroug F, Diehl JL, Elatrous S, Beuret P, et al. Noninvasive ventilation and weaning in patients with chronic hypercapnic respiratory failure: a randomized multicenter trial. Am J Respir Crit Care Med. 2011;184(6):672-9.

77. Burns KE, et al. Noninvasive ventilation as a weaning strategy for mechanical ventilation in adults with respiratory failure: a Cochrane systematic review. CMAJ. 2014;186(3):E112-22.

78. Hess DR, Branson RD. Know your ventilator to beat the leak. Chest. 2012;142(2):274-5.

79. Chandra D, Stamm JA, Taylor B, Ramos RM, Satterwhite L, Krishnan JA, et al. Outcomes of noninvasive ventilation for acute exacerbations of chronic obstructive pulmonary disease in the United States, 1998-2008. Am J Respir Crit Care Med. 2012;185(2):152-9.

80. Antonelli M, Conti G. Noninvasive positive pressure ventilation as treatment for acute respiratory failure in critically ill patients. Crit Care. 2000;4(1):15-22.

81. Stevenson NJ, Walker PP, Costello RW, Calverley PMA. Lung mechanics and dyspnea during exacerbations of chronic obstructive pulmonary disease. Am J Respir Crit Care Med. 2005;172(12): $1510-6$.

82. O'Donnell DE, Parker CM. COPD exacerbations - 3: pathophysiology. Thorax. 2006;61(4):354-61.

83. Rochwerg B, Brochard L, Elliott MW, Hess D, Hill NS, Nava S, ... Raoof S. M. O. T. T. F. Official ERS/ATS clinical practice guidelines: noninvasive ventilation for acute respiratory failure. Eur Respir J. 2017;50(2). https://doi.org/10.1183/13993003.024262016.

84. Sharp JT, Griffith GT, Bunnell IL, Greene DG. Ventilatory mechanics in pulmonary edema in man. J Clin Invest. 1958;37(1):111-7.

85. Bierer GB, Soo Hoo GW. Noninvasive ventilation for acute respiratory failure: a national survey of Veterans Affairs hospitals. Respir Care. 2009;54(10):1313-20.

86. Hess DR, Pang JM, Camargo CA Jr. A survey of the use of noninvasive ventilation in academic emergency departments in the United States. Respir Care. 2009;54(10):1306-12. 
87. Maheshwari V, Paioli D, Rothaar R, Hill NS. Utilization of noninvasive ventilation in acute care hospitals: a regional survey. Chest. 2006;129(5):1226-33.

88. Gay PC. Complications of noninvasive ventilation in acute care. Respir Care. 2009;54(2):246-57 discussion 257-8.

89. Bach JR, B.P, Hess DR, Hill NS, McIntyre N, Pearson D, et al. Consensus statement: noninvasive positive pressure ventilation. Respir Care. 1997;42:365-9.

90. Pang D, Keenan SP, Cook DJ, Sibbald WJ. The effect of positive pressure airway support on mortality and the need for intubation in cardiogenic pulmonary edema: a systematic review. Chest. 1998;114(4):1185-92.

91. Chiumello D. Is noninvasive ventilation still underused by physicians? Respir Care. 2009;54(10):1302-3.

Publisher's Note Springer Nature remains neutral with regard to jurisdictional claims in published maps and institutional affiliations. 